\title{
Vehicle Tracking and Locking System Based on GSM and GPS
}

\author{
R.Ramani ${ }^{1}$, S.Valarmathy ${ }^{1}$ \\ Department of ECE, V.M.K.V.Engineering College, TN, India \\ E-mail: ramani_gpt@yahoo.co.in \\ Dr. N.SuthanthiraVani tha ${ }^{1}$
}

Department of Electrical and Electronics Engineering, Knowledge institute of technology, Tamilnadu, India

\section{S.Selvaraju ${ }^{2}$, M.Thiruppathi ${ }^{2}$}

Department of ECE, V.M.K.V.Engineering College, Tamilnadu, India

\author{
R.Thangam ${ }^{3}$ \\ Department of Computer science Engineering, Saras wathi Engineering College and Technology, Tamilnad u, India
}

\begin{abstract}
Currently almost of the public having an own vehicle, theft is happening on parking and sometimes driving insecurity places. The safe of vehicles is extremely essential for public vehicles. Vehicle tracking and locking system installed in the vehicle, to track the place and locking engine motor. The place of the vehicle identified using Global Positioning system (GPS) and Global system mobile communication (GSM). These systems constantly watch a moving Vehicle and report the status on demand. When the theft identified, the responsible person send SMS to the microcontroller, then mic rocontroller issue the control signals to stop the engine motor. Authorized person need to send the password to controller to restart the vehicle and open the door. This is more secured, reliable and low cost.
\end{abstract}

Index Terms - Vehicle Tracking, Locking, Microcontroller, GPS, GSM

\section{Introduction}

In the last few decades, India has progressed at such an enormous rate that many companies have strongly established themselves here. These companies bring a huge amount of workforce with them. Arranging transportation to such a huge mass is a cumbersome task involving many intricacies. Generally, this transport is arranged through the local transport vendors on a yearly contract basis, recently happen mishaps such as burglary, rape cases etc. The development of satellite communication technology is easy to identify the vehicle locations. Vehicle tracking systems have brought this technology to the day-to-day life of the common person. Today GPS used in cars, ambulances, fleets and police vehicles are common sights on the roads of developed countries. All the existing technology support tracking the vehicle place and status

The GPS/GSM Based System is one of the most important systems, which integrate both GSM and GPS technologies. It is necessary due to the many of applications of both GSM and GPS systems and the wide usage of them by millions of people throughout the world [1]. This system designed for users in land construction and transport business, provides real-time information such as location, speed and expected arrival time of the user is moving vehicles in a concise and easy-to-read format. This system may also useful for communication process among the two points.

Currently GPS vehicle tracking ensures their safety as travelling. This vehicle tracking system found in clients vehicles as a theft prevention and rescue device. Vehicle owner or Police follow the signal emitted by the tracking system to locate a robbed vehicle in parallel the stolen vehicle engine speed going to decreased and pushed to off. After switch of the engine, motor cannot restart without permission of password. This system installed for the four wheelers, Vehicle tracking usually used in navy operators for navy management functions, routing, send off, on board information and security. The applications include monitoring driving performance of a parent with a teen driver. Vehicle tracking systems accepted in consumer vehicles as a theft prevention and retrieval device. If the theft identified, the system sends the SMS to the vehicle owner. After that vehicle owner sends the SMS to the controller, issue the necessary signals to stop the motor. In this paper, the revie wed related technology in section 3. The vehicle tracking and locking systems 
carried out in section 4. The conclusions, advantages and future scope in section 5.

\section{Survey of the Related Work}

In [2], the hardware and software of the GPS and GSM network were developed. The proposed GPS/GSM based System has the two parts, first is a mobile unit and another is controlling station. The system processes, interfaces, connections, data transmission and reception of data among the mobile unit and control stations are working successfully. These results are compatible with GPS technologies.

In [3], a vehicle tracking system is an electronic device, installed in a vehicle to enable the owner or a third party to track the vehicle's place. This paper proposed to design a vehicle tracking system that works using GPS and GSM technology. This system built based on embedded system, used for tracking and positioning of any vehicle by using Global Positioning System (GPS) and Global system for mobile communication (GSM). This design will continuously watch a moving Vehicle and report the status of the Vehicle on demand.

In [4], Face Detection System used to detect the face of the driver, and compare with the predefined face. The car owner is sleeping during the night time and someone theft the car. Then Face Detection System obtains images by one tiny web camera, which is hidden easily in somewhere in the car. Face Detection System compared the obtained images with the stored images. If the images don't match, then the information sends to the owner through MMS. The owners get the images of the thief in mobile phone and trace the place through GPS. The place of the car and its speed displayed to the owner through SMS. The owner can recognize the thief images as well as the place of the car and can easily find out the hijackers image. This systemapplied in our day-to-day life.

In [5], this system provided vehicle cabin safety, security based on embedded system by modify ing the existing modules. This method monitors the level of the toxic gases such as CO, LPG and alcohol within the vehicle provided alert information as alarm during the dangerous situations. The SMS sends to the authorized person through the GSM. In this method, the IR Sensor used to detect the static obstacle in front of the vehicle and the vehicle stopped if any obstacle detected. This is avoiding accidents due to collision of vehic les with any static obstacles.

In [6], Kai-Tai Song and Chih-Chieh Yang have a designed and built on a real-time visual tracking system for vehicle safety applications. In this paper built a novel feature-based vehicle-tracking algorithm, automatically detect and track several moving objects, like cars and motorcycles, ahead of the tracking vehicle. Joint with the concept of focus of expansion (FOE) and view analysis, the built system can segment features of moving objects from moving background and offer a collision word of warning on real-time. The proposed algorithm using a CMOS image sensor and NMOS embedded processor architecture. The constructed stand-alone visual tracking system validated in real road tests. The results provided information of collision warning in urban artery with speed about $60 \mathrm{~km} /$ hour both at night and day times.

In [7], the remote monitoring system based on SMS and GSM was implemented. Based on the total design of the system, the hardware and software designed. In this paper, the GSM network is a medium for transmitting the remote signal. This includes two parts that are the monitoring center and the remote monitoring station. The monitoring centers consist of a computer and communication module of GSM. The software-monitoring center and the remote monitoring station implemented by using VB. The result of this demonstration shows that the system can watch and control the remote communication between the monitoring center and the remote monitoring station.

In [8] this paper, the proposed tracking system based on cloud computing infrastructure. The sensors are used to monitor the fuel level, driver conditions, and speed of the vehicle. All the data transferred to cloud serverusing GSM enabled device. All the vehicles equipped with GPS antenna to locate the place. To avoid the drunk and drive, the alcohol sensor installed to monitor the driver status. The proposed technology significantly avoids the accident in highways.

\section{Proposed Method}

In this proposed work, a novel method of vehicle tracking and locking system used to track the theft vehicle by using GPS and GSM technology. This system puts into sleeping mode while the vehicle handled by the owner or authorized person otherwise goes to active mode, the mode of operation changed by in person or remotely. If any interruption occurred in any side of the door, then the IR sensor senses the signals and SMS sends to the microcontroller. The controller issues the message about the place of the vehicle to the car owner or authorized person. When send SMS to the controller, is sues the control signals to the engine motor. Engine motor speeds are gradually decreases and come to the off place. After that all the doors locked. To open the door or restart the engine, authorized person needs to enter the passwords. In this method, tracking of vehicle place easy and doors locked automatically, thereby thief cannot get away from the car.

\subsection{Block Diagram}

The Block diagram of Vehicle tracking and locking system based on GSM and GPS technology is shown in 
the figure1. It consists the power supply section, keyboard, GSM, GPS, mic rocontroller, MAX232driver, relay driver, IR Transmitter, IR receiver, LCD and door locker. The GSM board has a valid SIM card with a sufficient recharge amount to make outgoing calls. The circuits powered by $+5 \mathrm{v}$ Dc.

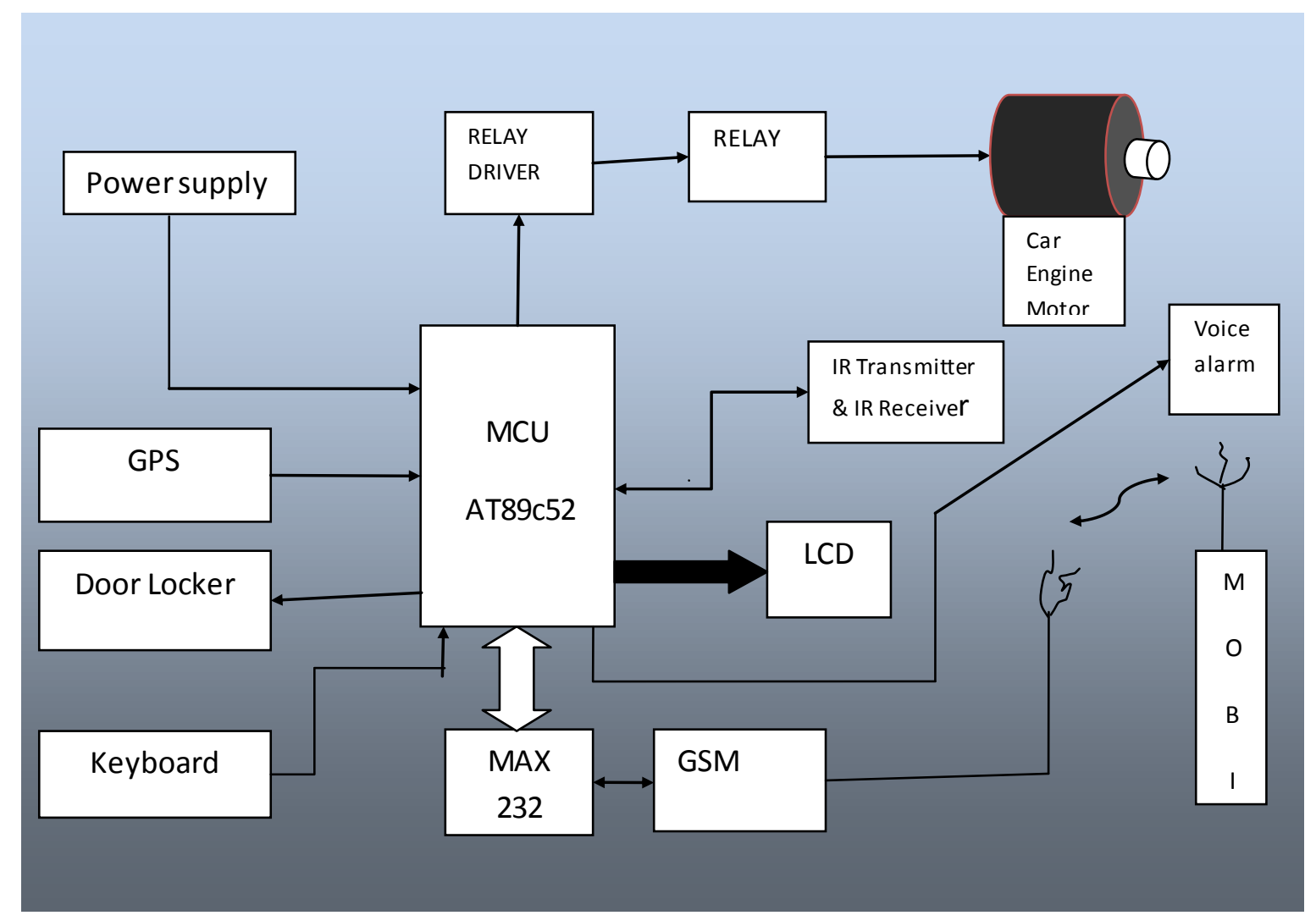

Fig. 1: Block diagram of Vehicle tracking and locking system based on GSM and GPS

\subsection{Circuit Descriptions}

The power supply section is very important for all electronic circuits. The $230 \mathrm{~V}, 50 \mathrm{~Hz}$ AC mains is stepped down by transformer X1 to deliver a secondary output of $12 \mathrm{~V}, 500 \mathrm{~mA}$. The transformer output is rectified by a full-wave rectifier comprising diodes D1 through $\mathrm{D} 4$, filtered by capacitor $\mathrm{C} 1$ and regulated by ICs 7812 (IC2) and 7805 (IC3). Capacitor C2 bypasses the ripples present in the regulated supply. LED1 acts as the power indicator and R1 limits the current through LED1.The power supply section is shown in the figure2.

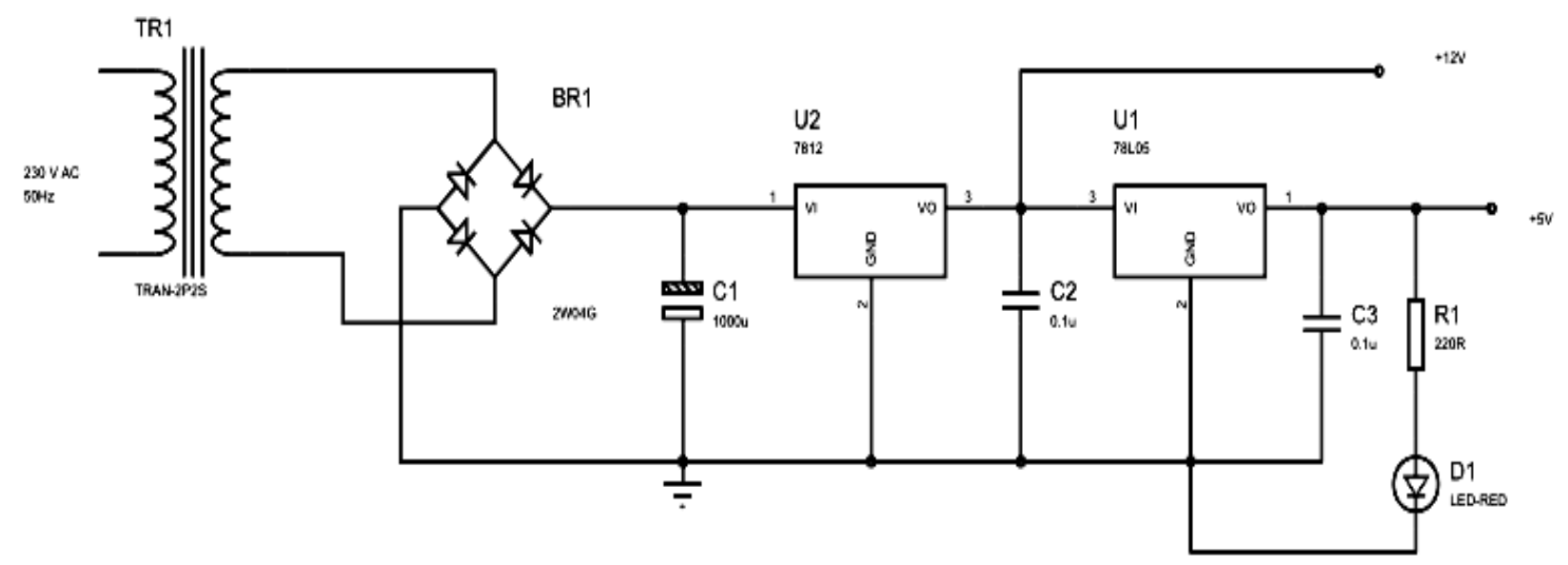

Fig. 2: power supply 
Proposed circuit diagram

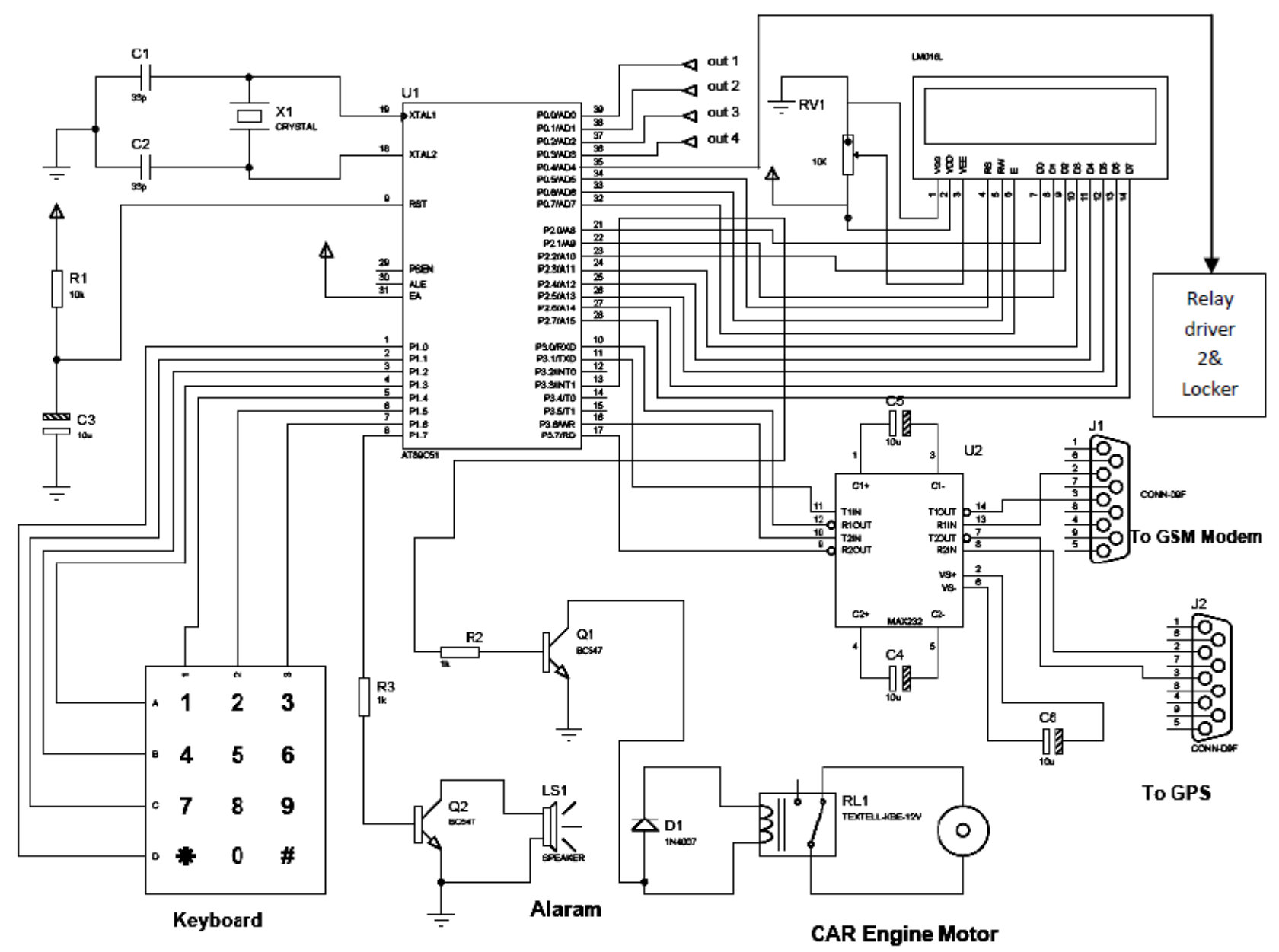

Fig. 3: circuit diagram of vehicle tracking and locking embedded system using GPS and GSM technology
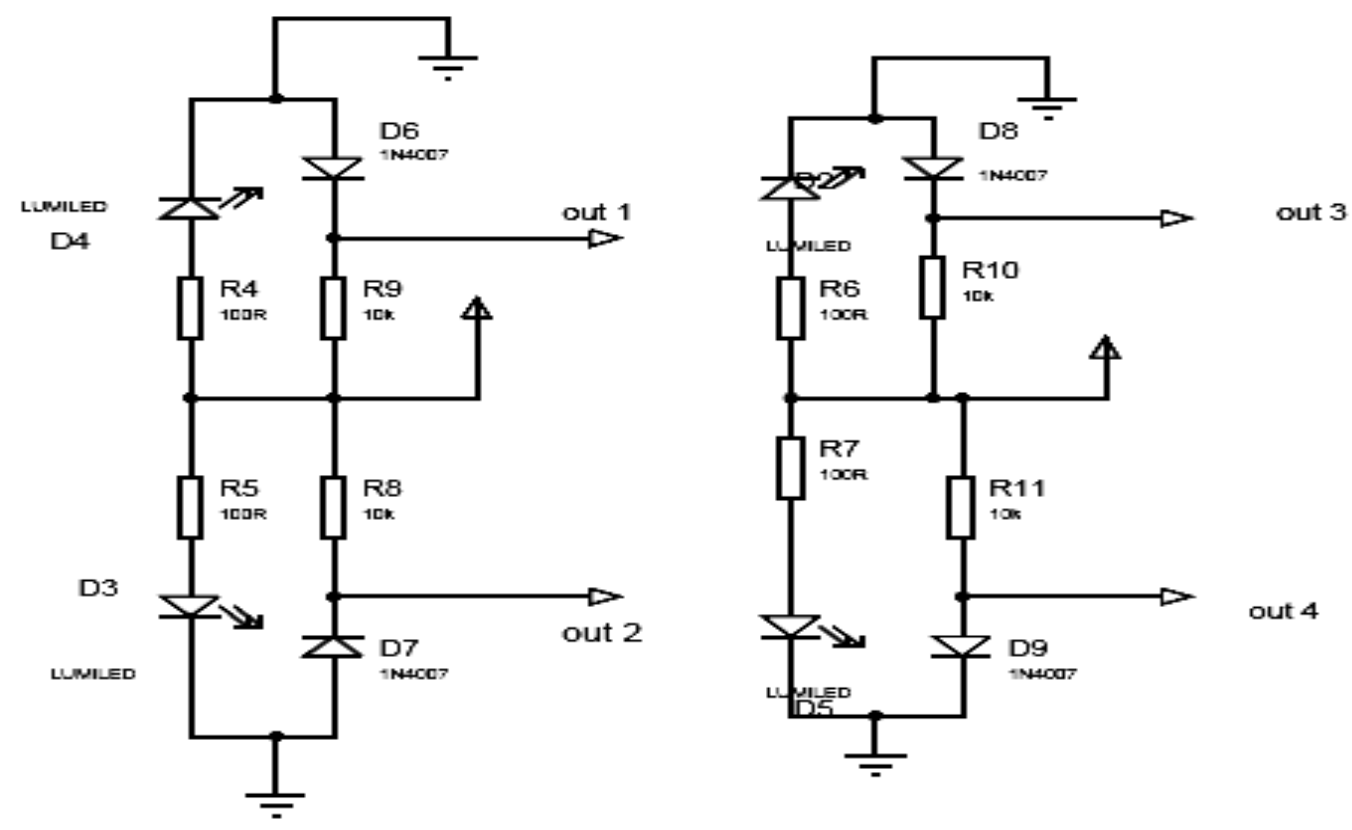

Fig. 4: Door sensor circuit 
The circuit diagram of the vehicle tracking and locking embedded system using GPS and GSM technology is shown in Fig.3.The compact circuitry is built around Atmel AT89C52 microcontroller. The AT89C52 is a low power; high performance CMOS 8bit microcomputer with $8 \mathrm{kB}$ of Flash programmable and erasable read only memory (PEROM). It has 256 bytes of RAM, 32 input/output (I/O) lines, three 16-b it timers/ counters, a six-vector two-level interrupt architecture a full-duplex serial port, an on-chip oscillator and clock circuit. The system clock also plays a significant role in operation of the mic rocontroller. An $11.0592 \mathrm{MHz}$ quartz crystal connected to pins 18 and 19 provides basic clock to the microcontroller. Power-on reset is provided by the combination of electrolytic capacitor C3 and resistor R1. Port pins P2.0 through P2.7 of the microcontroller are connected to data port pins D0 through D7 of the LCD, respectively. Port pins P0.5, P0.6 and P0.7 of the microcontroller are connected to Register-select (RS), Read / write (RW) and enable (E) pins of the LCD, respectively. All the data is sent to the LCD in ASCII format for display. Only the commands are sent in hex form. Registerselect (RS) signal is used to distinguish between data $(\mathrm{RS}=1)$ and command ( $R S=0)$. Preset $\mathrm{RV} 1$ is used to control the contrast of the LCD. Resistor 10k limits the current through the backlight of the LCD. Port pins P3.0 (RXD) and P3.1 (TXD) of the mic rocontroller are used to interface with the RFID reader through Max232 and GSM Modem are used to interface through Max232. Port pins from P1.0 to P2.7 of the microcontroller are connected to keyboard. The GPS and GSM are used to connect through RXD and TXD pins of the microcontroller for further processing. The port pins of P0.0 to P0.3 are used to connect the 4 IR sensors for detecting the unauthorized person. Port 1.7 is used to connect the alarm through transistor BC547, Pin number P3.3 is used to connect the engine motor. If unauthorized person enter into the car, the IR sensor sense the signals if any interruption occurs in any side of the door and send to the microcontroller, then the controller issue the message about the location of the vehicle to car owner or authorized person. When send the SMS to controller, issues the control signals to the engine motor. Engine motor speed is gradually decreases and comes to the off position. After that all the doors are locked. Pin P0.4 is used to connect the door locker through relay. To open the door or to restart the engine authorized person needs to enter the passwords. In this method, tracking of vehicle location easy and also doors are locked automatically thereby thief cannot get away from the car. Pin P0.4, transistor Q3 drives into saturation, and relay RL2 energizes to close or open the door lock.

\subsection{GPS Technology}

The Global Positioning System (GPS) is a satellitebased navigation system consists of a network of 24 satellites located into orbit. The system provides essential in formation to military, civil and commercial users around the world and which is freely accessible to anyone with a GPS receiver. GPS works in any weather circumstances at anywhere in the world. Normally no subscription fees or system charges to utilize GPS. A GPS receiver must be locked on to the signal of at least three satellites to estimate 2D position (latitude and longitude) and track movement. With four or more satellites in sight, the receiver can determine the user's 3D position (latitude, longitude and altitude). Once the vehicle position has been determined, the GPS unit can determine other information like, speed, distance to destination, time and other. GPS receiver is used for this research work to detect the vehicle location and provide information to responsible person through GSM technology.

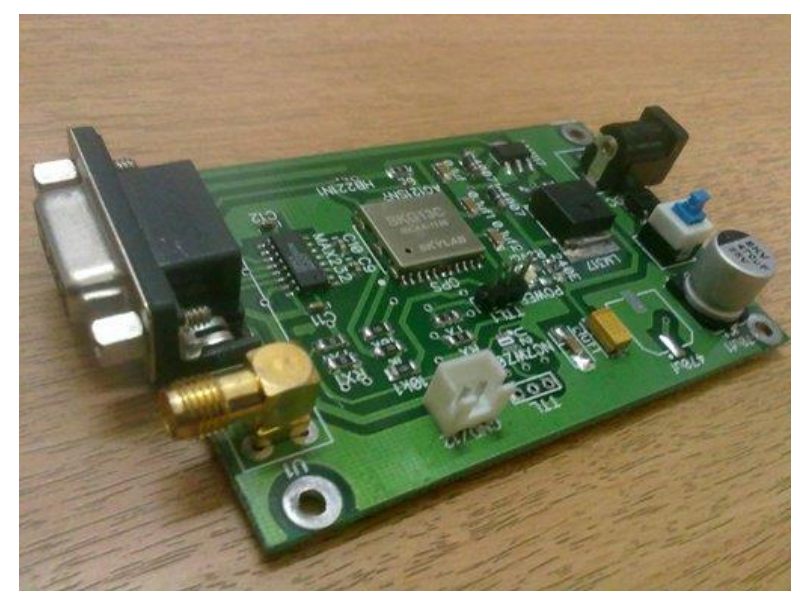

Fig. 5: GPS module

\subsection{GSM Modem SIM300 V7.03}

The GSM modem is a specialized type of modem which accepts a SIM card operates on a subscriber's mobile number over a network, just like a cellular phone. It is a cell phone without display. Modem $\operatorname{sim} 300$ is a triband GSM/GPRS engine that works on EGSM $900 \mathrm{MHz}$, DCS $1800 \mathrm{MHz}$ and PCS $1900 \mathrm{MHz}$ frequencies.GSM Modem is RS232-logic level compatible, i.e., it takes $-3 \mathrm{v}$ to $-15 \mathrm{v}$ as logic high and $+3 \mathrm{v}$ to +15 as logic low.MAX232 is used to convert TTL into RS232 logic level converter used between the microcontroller and the GSM board. The signal at pin 11 of the microcontroller is sent to the GSM modem through pin 11 of $\max 232$.this signal is received at pin2 (RX) of the GSM modem. The GSM modem transmits the signal from pin 3 (TX) to the microcontroller through MAX232, which is received at pin 10 of IC1 [9].

\section{Features of GSM}

$>$ Single supply voltage $3.2 \mathrm{v}-4.5 \mathrm{v}$

$>$ Typical power consumption in SLEEP Mode: $2.5 \mathrm{~mA}$.

SIM300 tri-band 


\begin{abstract}
$>\mathrm{MT}, \mathrm{MO}, \mathrm{CB}$, text and PDU mode, SMS storage: SIM card
\end{abstract}

$>$ Supported SIM Card :1.8V,3V

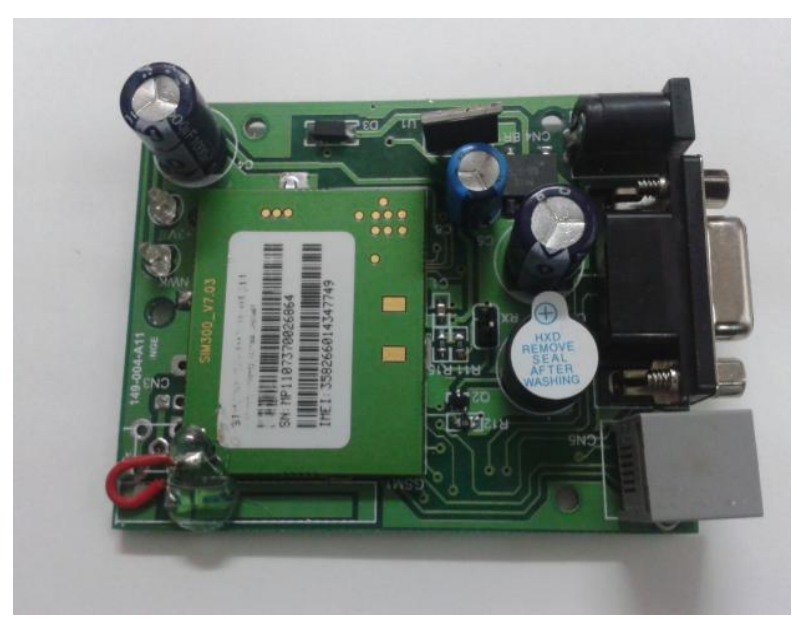

Fig. 6: GSM module

\section{Debugging and Testing Process}

A mic rocontroller-based system is a complex activity that involves hardware and software interfacing with the external world. Doing well design of a microcontroller-based system requires skills to use the variety of debugging and testing tools available. The debugging and testing of microcontroller-based systems divided into two groups: software-only tools and software-hardware tools. Software-only tools come as monitors and simulators, which are independent of the hardware under development. Software-hardware tools are usually hardware dependent, more expensive and range from in-circuit emulators and in-circuit simulators to in-circuit debuggers. In general, the higher the level of integration with the target hardware, the greater the benefit of a tool, resulting in a shorter development time, but the greater the cost as well. The factors to consider when choosing a debugging tool are cost, ease of use and the features offered during the debugging process.

A software simulator is a computer program running on an independent hardware and it simulates the CPU, the instruction set and the I/O of the target microcontroller. Simulators offer the lowest-cost development tools for microcontroller-based systems and most companies offer their simulator programs free of charge.

The user program operated in a simulated environment where the user can insert breakpoints within the code to stop the code and then analyze the internal registers and memory, display and change the values of program variables and so on. Incorrect logic or errors in computations can analyze by stepping through the code in simulation. Simulators run at speeds 100 to 1000 times slower than the actual mic ro controller hardware and, thus, long time delays should avoid when simulating a program. Micro controllerbased systems usually have interfaces to various external devices such as motors, I/O ports, timers, A/D converters, displays, push buttons, sensors and signal generators, which are usually difficult to simulate. Some advanced simulators, such as the Proteus from Labcenter Electronics allow the simulation of various peripheral devices such as motors, LCDs, 7-segment displays and keyboards, and users can create new peripheral devices. Inputs to the simulator can come from files that may store complex digital I/O signals and waveforms. Outputs can be as form of digital data or waveforms, usually stored in a file, or displayed on a screen. Some simulators accept only the assembly language of the target microcontroller. Most of the microcontroller software has written a high-level language such as $\mathrm{C}$, Pascal or Basic, and it has become necessary to simulate a program has written in a highlevel language.

The software program has written in c or assembly language and compiled using Keil software. After compiler operation, the hex code generated and stored in the computer. The hex code of the program should be loaded into the AT89C52 by using Top win Universal programmer.

\subsection{Hardware Assembling and Testing:}

First step, we need to make single side PCB layout for the given circuit diagram. After made the PCB the following process is required to complete the project.

1. Assemble all the components on the PCB based on circuit diagram. TX and RX pins of the GSM modem to pins 13 and 14 of MAX 232 and insert a valid SIM in the GSM modem.

2. Connect the GPS module according to circuit diagram.

3. This projects implemented and tested successfully by us.

4. This systemis very useful and secure for car owners.

\section{Conclusion}

In this paper, we have proposed a novel method of vehicle tracking and locking systems used to track the theft vehicle by using GPS and GSM technology. This system puts into the sleeping mode vehicle handled by the owner or authorized persons; otherwise goes to active mode. The mode of operations changed by persons or remotely. When the theft identified, the responsible people send SMS to the micro controller, then issue the control signals to stop the engine motor. After that all the doors locked. To open the doors or to restart the engine authorized person needs to enter the passwords. In this method, easily track the vehicle place and doors locked. 


\section{Acknowledgement}

The authors are sincerely thankful to the unanimous reviewers for their critical comments and suggestions to improve the quality of the manuscript.

\section{References}

[1] Chen, H., Chiang, Y. Chang, F., H. Wang, H. (2010). Toward Real-Time Precise Point Positioning: Differential GPS Based on IGS Ultra Rapid Product,SICE Annual Conference, The Grand Hotel, Taipei, Taiwan August 18-21.

[2] Asaad M. J. Al-Hindawi, Ibraheem Talib, "Experimentally Evaluation of GPS/GSM Based System Design", Journal of Electronic Systems Volume 2 Number 2 June 2012

[3] Kunal Maurya, Mandeep Singh, Neelu Jain, "Real Time Vehicle Tracking System using GSM and GPS Technology- An Anti-theft Tracking System," International Journal of Electronics and Computer Science Engineering. ISSN 22771956/V1N3-1103-1107

[4] Vikram Kulkarni \& Viswaprakash Babu, "embedded smart car security system on face detection', special issue of IJCCT, ISSN(Online):2231-0371, ISSN(Print):09757449 ,volume- 3 , is sue-1

[5] V.Ramya, B. Palaniappan, K. Karthick, "Embedded Controller for Vehicle In-Front Obstacle Detection and Cabin Safety Alert System", International Journal of Computer Science \& Information Technology (IJCSIT) Vol 4, No 2, April 2012.

[6] Kai-Tai Song, Chih-Chieh Yang, of National Chiao Tung University, Taiwan, "Front Vehicle Tracking Using Scene Analysis", Proceedings of the IEEE International Conference on Mechatronics \& Automation 2005.

[7] Chen Peijiang, Jiang Xuehua, "Design and Implementation of Remote monitoring system based on GSM," vol.42, pp.167-175. 2008.

[8] Albert Alexe, R.Ezhilarasie, "Cloud Computing Based Vehicle Tracking Information Systems", ISSN: 2229 - 4333 ( Print) | ISSN: 0976 - 8491 (Online ) IJCST Vol. 2, Iss ue 1, March 2011

[9] R.Ramani, S.Selvaraju, S.Valarmathy, R.Thangam B.Rajasekaran, "water-level monitor for bore well and water tank based on GSM", International Journal of engineering science and technology (IJEST), ISSN: 0975-5462, volume4-N0:10, october2012

\section{Authors' Profiles}

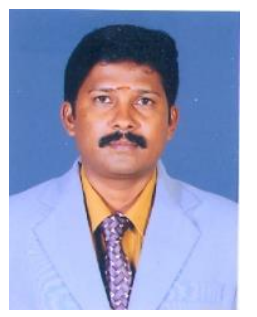

R.Ramani is working as Assistant Professor in the Department of Electronics and Communication Engineering, V.M.K.V. Engineering College, Salem. He has received $\mathrm{B}, \mathrm{E}$ degree in Electronics and Communication Engineering from GCE, Salem, Anna University, Chennai in 2006 and M.E in Communication Systems from Sona college of technology, Salem, Anna University, Chennai in 2008. He has 4 international journals published. His area of research interests includes image processing embedded systems.

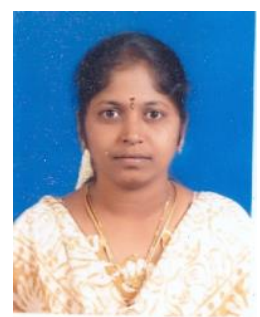

S.Valarmathy is working as Associate Professor in the department of electronics and communication engineering, V.M.K.V. Engineering College, Salem. She has received M.Sc., in Applied Electronics from Cheran arts and science, Bharthiyar University, Coimbatore in 2002 and M.E in Advanced Communication Systems from V.M.K.V. Engineering College, Vinayaka Missions University, Salem 2006. She has 4 international journals published. Her area of research interests includes image processing, embedded system.

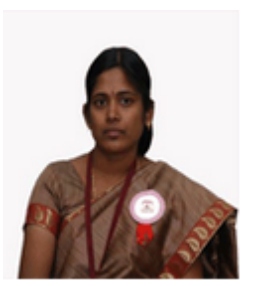

Dr.N.Suthanthira Vanitha is working as Professor and head in the department of electronics and electrical engineering at Knowledge Institute of Technology, Salem. She has received Ph.D, in Biomedical \& Embedded Systems from Anna University Chennai. 12 years teaching experiences and 15 international journals published in various field. Her area of research interests includes image processing, embedded systems, biomedical and networking.

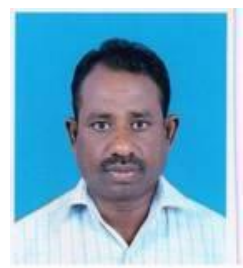

S.Selvaraju is working as Associate Professor in the department of Electronics and Communication engineering, V.M.K.V. Engineering College, Salem. He has received B.E, in electronics and communication engineering from Kongu Engineering College, affiliated to Bharthiyar University, Coimbatore in 1989 and M.E in Applied Electronics from V.M.K.V.Engineering College, affiliated to anna University, and Salem 2005. Her a rea of research interests includes embedded systems and networks communication 


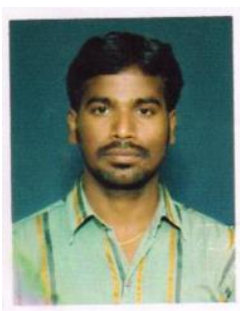

M.Thiruppathi is working as Assistant Professor in the Department of Electronics and Communication Engineering, V.M.K.V. Engineering College, Salem. He has received B, E degree in Electronics and Communication Engineering from Adhiparasakthi Engineering College, melmaruvathur, Anna University, Chennai in 2007 and M.E in Embedded System technology from Anna University, tirunelveli 2010. His area of research interest embedded systems.

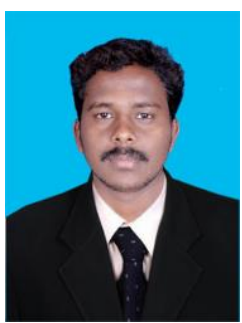

R.Thangam is working as Assistant Professor in the Department of computer science engineering at Saraswathi Engineering College and Technology. He has received M.C.A degree Madras University, Chennai and M.E in computer science at sri Krishna engineering college and technology, Coimbatore in 2010, Anna University. His area of research interest embedded systems and networks.

How to cite this paper: R.Ramani, S.Valarmathy, N.SuthanthiraVanitha, S.Selvaraju, M.Thiruppathi, R.Thangam," Vehicle Tracking and Locking System Based on GSM and GPS", International Journal of Intelligent Systems and Applications(IJISA), vol.5, no.9, pp.86-93, 2013. DOI: 10.5815/ijisa.2013.09.10 